\title{
MODEL KAPASITAS MASYARAKAT DALAM MENGHADAPI BENCANA MENGGUNAKAN ANALISIS REGRESI LOGISTIK ORDINAL
}

\author{
Jaka Nugraha $^{1}$, Fitri Nugraheni ${ }^{2}$, Irwan Nuryana Kurniawan ${ }^{3}$ \\ ${ }^{\text {I} P r o g r a m ~ S t u d i ~ S t a t i s t i k a ~ F M I P A-U I I, ~}$ \\ ${ }^{2}$ Program StudiTeknik Arsitektur FTSP-UII \\ ${ }^{3}$ Program Studi Psikologi-FPSB -UII \\ Email : jk.nugraha@gmail.com
}

\begin{abstract}
Abstrak
Indonesia secara geografis merupakan sebuah negara yang memiliki potensi bencana alam yang tinggi untuk berbagai jenis bencana seperti banjir, gempa, tanah longsor, kekeringan dan gunung berapi. Pengurangan resiko bencana sebuah daerah dapat dilakukan dengan meningkatkan kapasitas pemerintah dan masyarakat dalam melakukan mitigasi bencana. Pada makalah ini dibahas penyusunan model kapasitas masyarakat dalam menghadapi bencana menggunakan analisis regresi logistik ordinal. Model regresi disusun dengan menggunakan tiga variabel dependen yaitu (i) pengetahuan umum yang dimiliki tentang pengurangan resiko bencana alam yang disimbolkan dengan Y1 (ii) pengetahuan umum yang dimiliki tentang bagaimana menyelamatkan keluarga ketika terjadi bencana alam yang disimbolkan dengan Y2 (iii) upaya peningkatan kewaspadaan warga menghadapi bencana alam oleh pihak terkait disimbolkan dengan Y3. Variabel dependen Y1 dan Y2 dipengaruhi oleh Faktor Pengetahuan dan Faktor Rencana Aksi. Sedangkan variabel dependen Y3 dipengaruhi oleh Faktor kepemimpinan dan program, dan Faktor Fasilitas.
\end{abstract}

Kata-kata kunci : kapasitas, mitigasi, regresi logistik, SEM

Pendahuluan

Indonesia secara geografis merupakan sebuah negara yang memiliki potensi bencana alam yang tinggi untuk berbagai jenis bencana seperti banjir, gempa, tanah longsor, kekeringan dan gunung berapi. Untuk merespons kondisi tersebut, Pemerintah Indonesia membentuk Undang-Undang Nomor 24 Tahun 2007 Tentang Penanggulangan Bencana, pemerintah kemudian mengeluarkan Peraturan Presiden Nomor 8 Tahun 2008 tentang Badan Nasional Penanggulangan Bencana (BNPB). BNPB memiliki fungsi pengkoordinasian pelaksanaan kegiataan penanggulangan bencana secara terencana, terpadu, dan menyeluruh (http://www.bnpb.go.id/). Pedoman penyusunan rencana penanggulangan bencana telah diatur melalui peraturan BNPB Nomor 4 Tahun 2008.

Dalam menghitung resiko bencana sebuah daerah melibatkan aspek ancaman (hazard), kerentanan (vulnerability) dan kapasitas (capacity). Resiko akan berbanding lurus dengan kerentanan dan ancaman, dan berbanding terbalik dengan 
kapasitas mitigasi. Resiko bencana bisa diturunkan bila kapasitas mitigasi (ketahanan, kesiap-siagaan) bencana dari masyarakat meningkat. Dalam Peraturan Kepala BNPB Nomor 03 Tahun 2012 telah ditetapkan bagaimana mengukur dan meningkatkan kapasitas daerah yang kesiapsiagaan, dan peran lembaga terkait.

Alat ukur untuk mengetahui kemampuan orang per orang, rumah tangga dan kelompok masyarakat dalam menghadapi bencana sangat penting sebagai dasar evaluasi kesiapan daerah. Yohe dan Tol (2002) mengusulkan sebuah metode untuk mengembangkan indikator kapasitas sosial dan ekonomi dalam konteks perubahan iklim. Kapasitas adaptasi yang digunakan oleh Ionescu dkk. (2007) hanya memasukkan pendapatan regional bruto, angka melek huruf, dan tingkat partisipasi tenaga kerja wanita. Yohe dkk. (2006) menggunakan Vulnerability-Resilience Indicator Prototype (VRIP). Iglesias $\mathrm{dkk}$ (2007b) telah mengembangkan indeks kerentanan sosial terhadap kekeringan. Kesiapan masyarakat merupakan proses atau serangkaian kegiatan yang dilakukan sebagai upaya untuk menghilangkan dan/atau mengurangi ancaman bencana yang memiliki beberapa tahapan. Model Kesiapan Masyarakat (Community Readiness Model) telah dibuat untuk melihat respon masyarakat atas intervensi menekankan aspek aspek kebijakan,

kebijakan/program (Edwards dkk., 2000 dalam Yuda, 2013).

Kapasitas adalah kemampuan daerah dan masyarakat untuk melakukan tindakan pengurangan ancaman dan potensi kerugian akibat bencana secara terstruktur, terencana dan terpadu. Kesiapsiagaan adalah serangkaian kegiatan yang dilakukan sebagai upaya untuk menghilangkan dan/atau mengurangi ancaman bencana. Nugraha dkk (2015) dengan menggunakan analisis Structural Equation Modeling (SEM) telah membuktikan keterkaitan antara Kapasitas Masyarakat dan Kesiapsiagaan dalam menghadapi bencana alam. Kapasitas masyarakat meliputi aspek Sosial, Fisik/ Lingkungan dan Ekonomi. Kesiapsiagaan terdiri dari kesiap-siagaan individu dan Kesiapsiagaan Masyarakat. Kesiapsiagaan individu meliputi aspek rencana, pengetahuan dan sikap. Kesiapsiagaan masyarakat meliputi kepemimpinan, informasi, fasilitas. Pada makalah ini dibahas penyusunan indek kapasitas masyarakat dalam menghadapi bencana menggunakan analisis regresi logistik ordinal.

\section{Indikator Kapasitas Masyarakat}

Kapasitas masyarakat adalah kemampuan masyarakat untuk melakukan tindakan pengurangan ancaman dan potensi kerugian akibat bencana. Kapasitas masyarakat dapat ditinjau dari dua aspek Model Kapasitas Masyarakat Dalam Menghadapi Bencana Menggunakan Analisis Regresi Logistik Ordinal (Jaka Nugraha, Fitri Nugraheni, Irwan Nuryana Kurniawan) 
yaitu kapasitas individu dan dan kapasitas kelembagaan sebagaimana dijelaskan dalam Gambar 1. Kapasitas individu dipengaruhi oleh pengetahuan, budaya (kearifan lokal) dan rencana aksi. Kapasitas kelembagaan dipengaruhi oleh adanya program, informasi, kepemimpinan, kearifan lokal dan fasilitas.

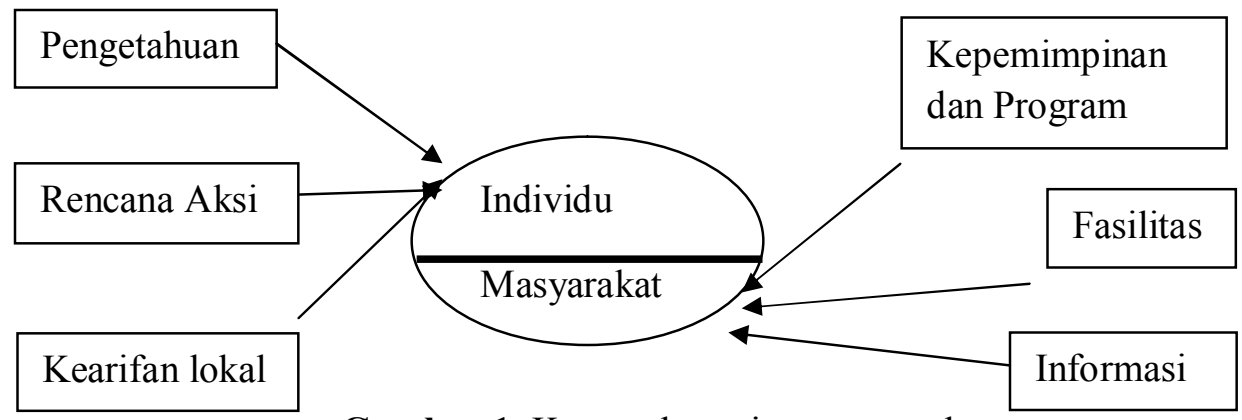

Gambar 1. Konsep kapasitas masyarakat.

Konsep kapasitas masyarakat yang dijelaskan dalam Gambar 1. akan diuji menggunakan analisis regresi logistik ordinal.

\section{Regresi Logistik Ordinal}

\section{Model Regresi Logistik Ordinal} sering dikenal dengan model logit kumulatif. Pada model ini, variabel respon $\mathrm{Y}$ berupa data ordinal dengan $\mathrm{k}$ kategori, variabel independen dapat berupa variabel kategori, kontinyu atau campuran keduanya yang disimbolkan dengan $X^{\prime}=$ $\left(\mathrm{X}_{1}, \mathrm{X}_{2}, ., \mathrm{X}_{\mathrm{p}}\right)$. Pada model ini didefinisikan fungsi logit:

$\pi_{j}=P(Y=j)=\frac{\exp \left(\theta_{j}+X^{\prime} \beta\right)}{1+\exp \left(\theta_{j}+X^{\prime} \beta\right)} \quad$ dan

$P(Y \leq j)=\pi_{1}+\pi_{2}+\cdots+\pi_{j}$

$\pi_{\mathrm{j}}$ adalah peluang $\mathrm{Y}=\mathrm{j}$ dan $\theta_{\mathrm{j}}, \beta$ merupakan parameter dari koefisien regresi. Transformasi linearnya adalah: $\ln \left(\frac{P(Y \leq j)}{1-P(Y \leq j)}\right)=\theta_{j}+X^{\prime} \beta$ dengan $\mathrm{j}=1,2,3, \ldots, \mathrm{k}-1$. Inferensi terhadap parameter-parameternya dapat diuji menggunakan uji Statistik Rasio Likelihood untuk uji simultan dan statistik uji Wald untuk uji parsial (Agresti, 2002).

\section{Data Percobaan}

Untuk menyusun indeks kapasitas masyarakat dalam menghadapi bencana dilakukan survey menggunakan kuesioner. Penyebaran kuesiener kepada masyarakat dilakukan secara acak dibeberapa provinsi wilayah Indonesia. Pengamatan terhadap masyarakat untuk mendapatkan data variabel dependen mengenai

(i) pengetahuan umum yang dimiliki tentang pengurangan resiko bencana alam yang disimbolkan dengan Y1.

(ii) pengetahuan umum yang dimiliki tentang bagaimana menyelamatkan 
keluarga ketika terjadi bencana alam yang disimbolkan dengan Y2.

(iii) upaya peningkatan kewaspadaan warga menghadapi bencana alam oleh pihak terkait yaitu Pemerintah (Y3a), Lembaga Swadaya Masyarakat (Y3b), Masyarakat Lokal/ Setempat (Y3c) dan Responden/ Rumah Tangga Responden (Y3d).

Variabel dependen ini bernilai $1=$ "sangat tidak puas", 2= “tidak puas", 3= ”cukup", 4= "puas", 5= "sangat puas". Variabel independen untuk Y1 dan Y2 adalah

(i) Pengetahuan Mitigasi disimbolkan dengan A, yang meliputi

- Pengetahuan bencana secara umum

- Pengetahuan menyelamatkan diri dari bencana

- Pengalaman mengikuti pelatihan/ seminar/ simulasi tentang kesiapsiagaan bencana

- Pengalaman mengalami bencana alam

- Pengetahuan tentang tempat tinggal yang merupakan daerah rawan bencana

- Pengetahuan keluarga tentang bencana alam

(ii) Rencana Aksi yang disimbolkan dengan $\mathrm{C}$ yang meliputi

- Persiapan mengamankan barang berharga - Persiapan rencana penyelamatan diri dari bencana (iii) Kearifan Lokal yang disimbolkan dengan $\mathrm{D}$ yang meliputi persepsi dan motivasi

Variabel independen untuk Y3 adalah

(iv) Kepemimpinan dan Program yang disimbolkan dengan $\mathrm{E}$,

- Upaya yang dilakukan pemerintah daerah setempat dalam peningkatan kewaspadaan bencana

- Pihak yang bertanggung jawab dalam persiapan menghadapi bencana

- Upaya yang dilakukan pemerintah daerah setempat dalam mengurangi risiko bencana - Pendekatan manajemen penanggulangan bencana

- Upaya pemerintah dalam peringatan dini bencana

(v) Informasi yang disimbolkan dengan $\mathrm{F}$

- Peran media dalam kesiapsiagaan bencana

- Sumber informasi dan media

(vi) Fasilitas yang disimbolkan dengan G.

- Kesediaan jalur evakuasi

- Kesediaan fasilitas peringatan dini

\section{Hasil dan Pembahasan}

Diperoleh data responden sebanyak 197 responden yang berasal 114 kabupaten 28 provinsi di seluruh wilayah indonesia. Persentase responden mengalami peristiwa masing-masing jenis bencana alam (gempa bumi, banjir, cuaca ekstrim, kekeringan, tsunami, tanah longsor, letusan gunung api, gelombang ekstrim, kebakaran) disajikan dalam Gambar 2. 


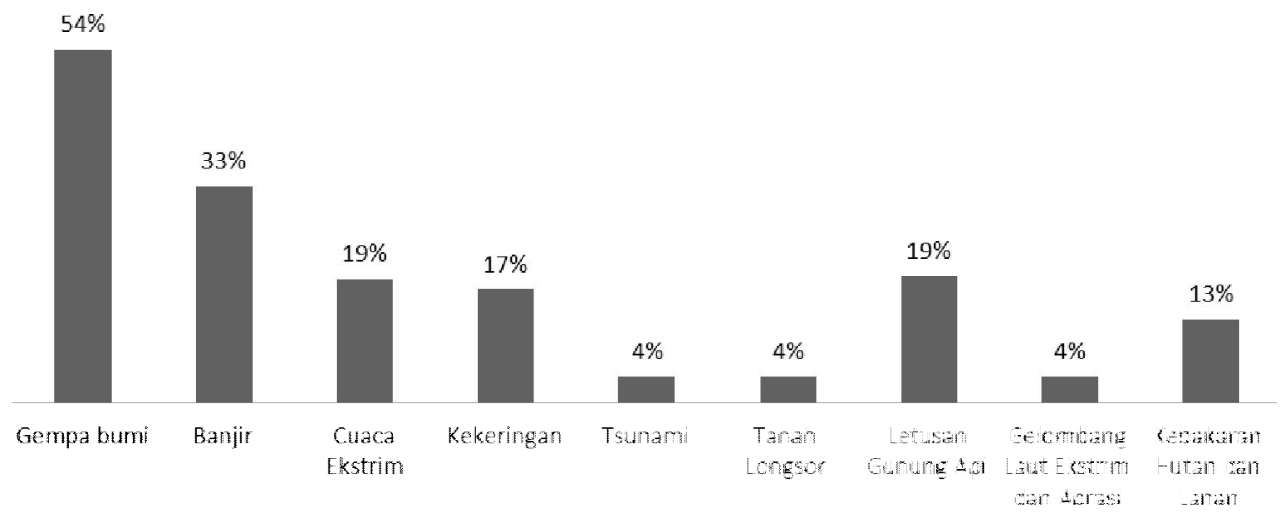

Gambar 2. Persentase responden mengalami peristiwa masing-masing bencana.

Berdasarkan hasil survei terhadap 197 responden diperoleh distribusi frekuensi Y1 dan Y2 disajikan dalam Tabel 1. yang menunjukkan bahwa lebih dominan Y1=3 yaitu 118 dari 197 responden (sebesar 59,9\%).

Tabel 1. Distribusi frekuensi Y1 dan Y2

\begin{tabular}{|c|c|c|c|c|c|c|c|}
\hline \multicolumn{2}{|c|}{} & \multicolumn{5}{|c|}{ Y2 } & \multirow{2}{*}{ Total } \\
\cline { 2 - 7 } \multicolumn{2}{|c|}{} & 1 & 2 & 3 & 4 & 5 & \\
\hline \multirow{3}{*}{ Y1 } & 1 & 1 & 0 & 2 & 1 & 0 & 4 \\
\cline { 2 - 7 } & 2 & 0 & 9 & 7 & 1 & 0 & 17 \\
\cline { 2 - 7 } & 3 & 1 & 11 & 80 & 24 & 2 & 118 \\
\cline { 2 - 7 } & 4 & 0 & 0 & 9 & 40 & 5 & 54 \\
\cline { 2 - 7 } & 5 & 0 & 0 & 0 & 0 & 4 & 4 \\
\hline \multicolumn{2}{|c|}{ Total } & 2 & 20 & 98 & 66 & 11 & 197 \\
\hline
\end{tabular}

Distribusi frekuensi Y3 disajikan dalam Tabel 2. yang menunjukan bahwa distribusi Y3a relatif sama dengan distribusi Y3b dan distribusi Y3c relatif sama dengan distribusi Y3d. Hal ini menunjukan bahwa responden berpendapat bahwa upaya peningkatan kewaspadaan warga menghadapi bencana alam oleh pihak Pemerintah selatif sama dengan
Lembaga Swadaya Masyarakat. Demikian juga upaya yang telah dilakukan oleh Masyarakat Lokal/Setempat relatif sama dengan upaya secara Individu/Rumah Tangga Responden.

Tabel 2. Distribusi frekuensi Y3

\begin{tabular}{|c|c|c|c|c|c|c|}
\hline Y3 & 1 & 2 & 3 & 4 & 5 & Total \\
\hline A & 8 & 44 & 105 & 38 & 2 & 197 \\
\hline B & 8 & 60 & 89 & 39 & 1 & 197 \\
\hline C & 7 & 13 & 102 & 63 & 12 & 197 \\
\hline D & 5 & 11 & 103 & 62 & 16 & 197 \\
\hline \multicolumn{6}{c|}{ Analisis regresi logistik ordinal }
\end{tabular}

digunakan untuk menyusun model yang dapat menjelaskan hubungan indepeden terhadap variabel dependen $\mathrm{Y}$ yang berupa data ordinal. Variabel dependen Y1 dan Y2 menggunakan variabel independen: A (Pengetahuan Mitigasi), C (Rencana Aksi) dan D (Kearifan Lokal).

Pengujian dilakukan pada beberapa model, ternyata hanya variabel C (rencana aksi) yang berpengaruh terhadap variabel Y1 dengan nilai estimasi parameter beserta statistik uji dalam Tabel 3. 
Tabel 3. Estimasi parameter dan statistik uji untuk variabel Y1.

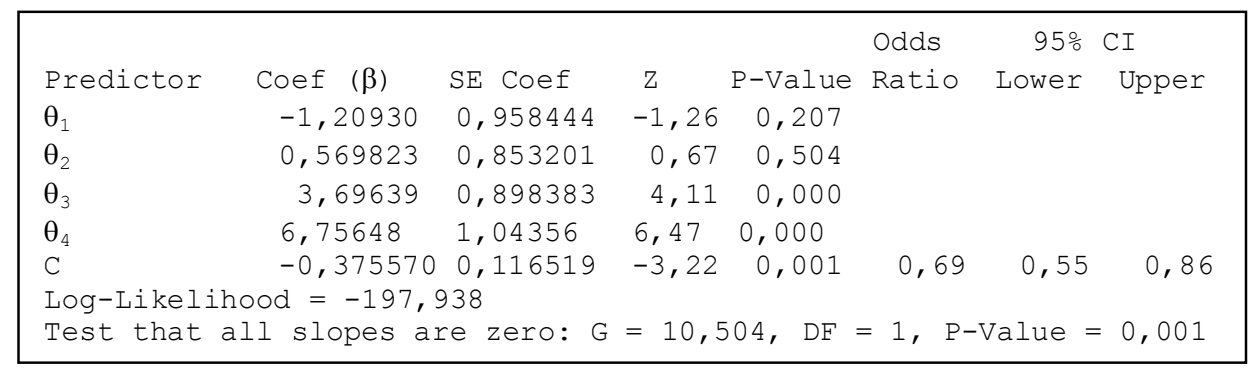

Persamaan regresi logistiknya adalah:

$\mathrm{P}(\mathrm{Y} 1 \leq \mathrm{j})=\frac{\exp (\theta \mathrm{j}-0,37557 . \boldsymbol{\sigma})}{1+\exp (\theta \mathrm{j}-0,37557 . \boldsymbol{\sigma})}$

dengan $\mathrm{j}=1,2,3,4,5 . \quad j=1$ : "sangat tidak puas", $j=2$ : “tidak puas”, $j=3$ : ”cukup”, j=4: “puas", $j=5$ : “sangat puas". Pada Tabel 3 diperoleh nilai $\theta_{1}=-1,20930$ dan $\theta_{2}=0,569823$ dengan masing-masing mempunyai $\mathrm{p}$-value $>\alpha=0,05$ yaitu 0,207 dan 0,504. Hal ini mengindikasikan bahwa $\mathrm{Y} 1=1$ dan $\mathrm{Y} 1=2$ tidak memiliki perbedaan signifikan dengan $\mathrm{Y} 1=3$.

Selanjutnya dilakukan pengujian model pada variabel dependen Y2. Diperoleh model terbaiknya adalah:
$\mathrm{P}(\mathrm{Y} 2 \leq \mathrm{j})=$

$\frac{\exp (\theta j+0,122230 A 3-0,22577 \text { A5 }-0,50786 C)}{1+\exp (\theta j+0,122230 A 3-0,22577 \& 5-0,50786 C y}(4)$

Variabel Y2 dipengaruhi oleh variabel C (rencana aksi), A3 (Pengalaman pelatihan) dan A5 (Pengetahuan tentang tempat tinggal yang merupakan daerah rawan bencana). Berdasarkan nilai estimasi parameter dalam Tabel 4 , nilai $\theta_{1}$ $=-0,940242$ dan $\theta_{2}=1,58527$ dengan masing-masing mempunyai p-value $>\alpha=0,05$ yaitu 0,378 dan 0,061 . Oleh karena itu dapat disimpulkan bahwa Y2=1 dan $Y 2=2$ tidak memiliki perbedaan signifikan dengan $\mathrm{Y} 2=3$.

Tabel 4. Estimasi parameter dan statistik uji untuk variabel Y2.

\begin{tabular}{|lccccccc|}
\hline & & & & & Odds & $95 \%$ \\
Predictor & Coef $(\boldsymbol{\beta})$ & $\boldsymbol{S E}$ Coef & $\boldsymbol{Z}$ & $\boldsymbol{P}$-Value & Ratio & Lower & Upper \\
$\theta_{1}$ & $-0,940242$ & 1,06723 & $-0,88$ & 0,378 & & & \\
$\theta_{2}$ & 1,58527 & 0,846678 & 1,87 & 0,061 & & & \\
$\theta_{3}$ & 4,33608 & 0,895478 & 4,84 & 0,000 & & & \\
$\theta_{4}$ & 6,93603 & 0,983647 & 7,05 & 0,000 & & & \\
A3 & 0,122230 & 0,0621591 & 1,97 & 0,049 & 1,13 & 1,00 & 1,28 \\
A5 & $-0,225777$ & 0,106304 & $-2,12$ & 0,034 & 0,80 & 0,65 & 0,98 \\
C & $-0,507867$ & 0,120289 & $-4,22$ & 0,000 & 0,60 & 0,48 & 0,76 \\
Log-Likelihood = -214,184 & & & & & \\
Test that all slopes are zero: $\mathrm{G}=26,170, \mathrm{DF}=3$, P-Value $=0,000$ \\
\hline
\end{tabular}

Variabel dependen ketiga adalah tingkat kepuasan responden terhadap pihat terkait dalam upaya peningkatan kewaspadaan warga menghadapi bencana alam. Pihak terkait yang dimaksud adalah
a. Pemerintah Pusat/Daerah (Y3a)
b. LSM dan Lembaga Internasional (Y3b)

Model Kapasitas Masyarakat Dalam Menghadapi Bencana Menggunakan Analisis Regresi Logistik Ordinal (Jaka Nugraha, Fitri Nugraheni, Irwan Nuryana Kurniawan) 
c. Masyarakat Lokal/Setempat (Y3c)

d. Responden dan Rumah Tangga

Responden (Y3d)

Model untuk variabel Y3 disusun dengan memperhatikan variabel independen: kesiapan masyarakat yaitu E (Kepemimpinan dan Program), F (Informasi) dan G (Fasilitas). Dari beberapa model yang diuji, diperoleh model terbaik dengan nilai estimasi parameter disajikan pada Tabel $5 \mathrm{~s} / \mathrm{d}$ Tabel 8. Berdasarkan Tabel 5, nilai $\theta_{1}=$ 0,45695 dengan p-value sebesar 0,531> $\alpha=0,05$ yang berarti bahwa tidak ada perbedaan signifikan antara $\mathrm{Y} 3 \mathrm{a}=1$ dengan $\mathrm{Y} 3 \mathrm{a}=2$. Variabel $\mathrm{Y} 3 \mathrm{a}$ dipengaruhi oleh variabel $\mathrm{E}$ dan $\mathrm{G}$.

Tabel 5. Estimasi parameter dan statistik uji untuk variabel Y3a

$\begin{array}{lccrrrrr}\text { Odds } & 95 \% & \boldsymbol{C} & & & & & \\ \text { Predictor } & \text { Coef }(\boldsymbol{\beta}) & \boldsymbol{S E} \text { Coef } & \boldsymbol{Z} & \boldsymbol{P} & \text { Ratio } & \text { Lower } & \text { Upper } \\ \theta_{1} & -0,45697 & 0,729772 & -0,63 & 0,531 & & & \\ \theta_{2} & 1,40269 & 0,680419 & 2,06 & 0,039 & & & \\ \theta_{3} & 4,25783 & 0,760624 & 5,60 & 0,000 & & & \\ \theta_{4} & 7,60462 & 1,04617 & 7,27 & 0,000 & & & \\ \mathrm{E} & -0,374445 & 0,111410 & -3,36 & 0,001 & 0,69 & 0,55 & 0,86 \\ \mathrm{G} & -0,0833341 & 0,0409014 & -2,04 & 0,042 & 0,92 & 0,85 & 1,00 \\ \text { Log-Likelihood = -196,588 } & & & & & \\ \text { Test that all slopes are zero: } \mathrm{G}=23,181, \mathrm{DF}=2, \text { P-Value }=0,000\end{array}$

Persamaan regresi untuk variabel Y3a adalah:

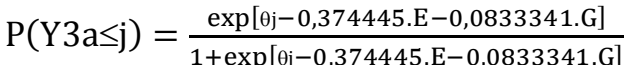

Berdasarkan Tabel 6, variabel Y3b hanya dipengaruhi oleh variabel E. Nilai $\theta_{1}=$ -
0,4633 dengan p-value sebesar 0,520 $>\alpha=0,05$ yang berarti bahwa tidak ada perbedaan signifikan antara $\mathrm{Y} 3 \mathrm{~b}=1$ dengan $\mathrm{Y} 3 \mathrm{~b}=2$.

Tabel 6. Estimasi parameter dan statistik uji untuk variabel Y3b.

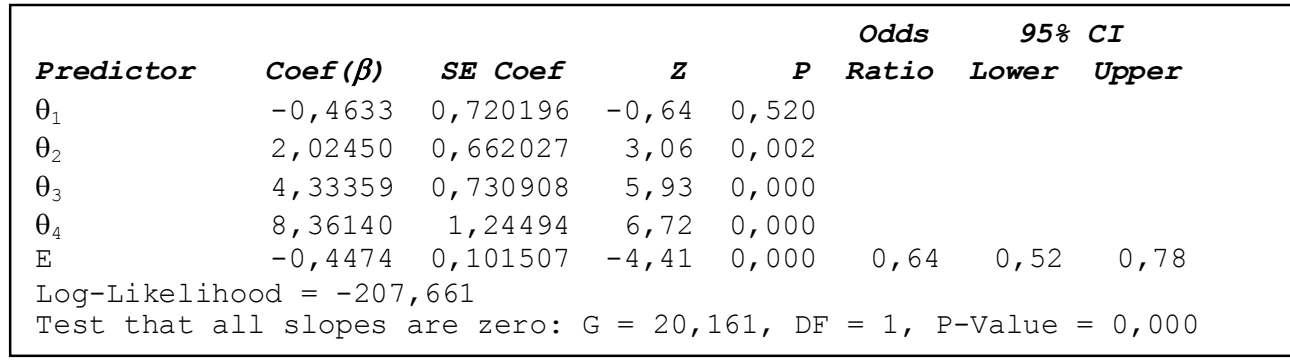

Persamaan regresi untuk variabel Y3b

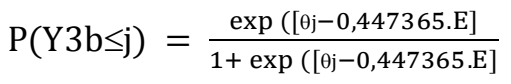
adalah: 
Tabel 9. Menentukan nilai IKM

\begin{tabular}{|c|c|c|c|c|c|c|}
\hline \multirow{2}{*}{ Skala } & \multicolumn{6}{|c|}{ Proporsi $\left(\pi_{\mathrm{i}}\right)$} \\
\cline { 2 - 7 } & Y1 & Y2 & Y3a & Y3b & Y3c & Y3d \\
\hline 1 & 0,020 & 0,010 & 0,041 & 0,041 & 0,036 & 0,025 \\
\hline 2 & 0,086 & 0,102 & 0,223 & 0,305 & 0,066 & 0,056 \\
\hline 3 & 0,599 & 0,497 & 0,533 & 0,452 & 0,518 & 0,523 \\
\hline 4 & 0,274 & 0,335 & 0,193 & 0,198 & 0,320 & 0,315 \\
\hline 5 & 0,020 & 0,056 & 0,010 & 0,005 & 0,061 & 0,081 \\
\hline Indeks & 3,188 & 3,325 & 2,909 & 2,822 & 3,305 & 3,371 \\
\hline IKM (\%) & 55,148 & 58,541 & 48,239 & 46,103 & 58,038 & 59,671 \\
\hline
\end{tabular}

Tingkat pengetahuanumum yang dimiliki tentang pengurangan resiko bencana alam baru mencapai 55,148\%, tingkat pengetahuan umum yang dimiliki tentang bagaimana menyelamatkan keluarga ketika terjadi bencana alam sebesar 58,541. Berdasarkan persepsi masyarakat, upaya peningkatan kewaspadaan warga menghadapi bencana alam oleh pihak terkait yaitu

a. Pemerintah (Y3a) sebesar 48,239,

b. Lembaga Swadaya Masyarakat (Y3b) sebesar 46,103,

c. Masyarakat Lokal/Setempat (Y3c) sebesar 58,038

d. Responden/Rumah Tangga Responden (Y3d) sebesar 59,671

\section{Kesimpulan}

Model kapasitas masyarakat dapat disusun dengan menggunakan model regresi logistik ordinal. Model regresi disusun dengan menggunakan tiga variabel dependen yaitu (i) pengetahuan umum yang dimiliki tentang pengurangan resiko bencana alam yang disimbolkan dengan Y1 (ii) pengetahuan umum yang dimiliki tentang bagaimana menyelamatkan keluarga ketika terjadi bencana alam yang disimbolkan dengan Y2 (iii) upaya peningkatan kewaspadaan warga menghadapi bencana alam oleh pihak terkait yaitu Pemerintah (Y3a), Lembaga Swadaya Masyarakat (Y3b), Masyarakat Lokal/ Setempat (Y3c) dan Responden/ Rumah Tangga Responden (Y3d). Dari data dan model yang diperoleh dapat disimpulkan:

1. Upaya peningkatan kewaspadaan masyarakat dalam menghadapi bencana alam yang dilakukan oleh pihak Pemerintah relatif sama dengan Lembaga Swadaya Masyarakat. Demikian juga upaya yang telah 
dilakukan oleh Masyarakat

Lokal/Setempat relatif sama dengan Individu/Rumah Tangga Responden.

2. Variabel dependen Y1 hanya dipengaruhi oleh faktor Rencana Aksi (C). Sedangkan varaibel dependen Y2 dipengaruhi oleh Faktor Faktor Pengetahuan (A) dan Faktor Rencana $\operatorname{Aksi}(\mathrm{C})$.

3. Variabel dependen Y3 tidak dipengaruhi oleh Faktor Informasi (F).

4. Variabel dependen Y3a dipengaruhi oleh Faktor Kepemimpinan dan Program (E) dan Faktor Fasilitas (G).

5. Variabel dependen Y3b, Y3c dan Y3d hanya dipengaruhi oleh Faktor Kepemimpinan dan Program (E).

6. Berdasarkan model regresi logistik ordinal dapat disusun sebuah ukuran indeks kapasitas masyarakat yang mempunyai nilai antara $0 \mathrm{~s} / \mathrm{d} 100 \%$.

\section{Ucapan Terimakasih}

Penelitian ini disponsori oleh Hibah Penelitian Unggulan Perguruan Tinggi No

Kontrak: 049/Rek/70/DPPM/Unggulan Perguruan Tinggi-DIKTI/III/2015 Tahun 2015.

\section{Referensi}

Agresti A., 2002, Categorical Data Analysis, John Wiley and Son

Ionescu, C., Klein, R.J.T., Hinkel, J., Kumar, K.S.K. dan Klein, R. (2007) "Towards a formal framework of vulnera- bility to climate change" Environmental Modeling and Assessment.

Iglesias A., Mougou R. danMoneo M. (2007b) "Adaptation of Mediterranean agriculture to climate change", Key vulnerable regions and climate change, European Climate Forum, Germany.

Nugraha J., Nugraheni F., Kurniawan IN, (2015), "Indikator Kapasitas Masyarakat Dan Kesiap-Siagaan Bencana", Prosiding Konferensi Nasional II Forum WahanaTeknologi di Daerah Istimewa Yogyakarta

PeraturanKepala BNPB Nomor 03 Tahun 2012 tentang panduan penilaian kapasitas daerah dalam penanggulangan bencana

Peraturan BNPB Nomor 4 Tahun 2008 tentang pedoman penyusunan rencana penanggulangan bencana.

Peraturan Presiden Nomor 8 Tahun 2008 tentang Badan Nasional Penanggulangan Bencana

Undang-UndangNomor 24 Tahun 2007 Tentang Penanggulangan Bencana

Yohe, G., Malone, E., Brenkert, A., Schlesinger, M., Meij, H. dan Xing, X., (2006), "Global Distributions of Vulnerability to Climate Change" Integrated Assessment Journal, 6 (3): 35-44.

Yohe, G. danTol, R.S.J. (2002), "Indicators for social and economic coping capacity: Moving toward a working definition of adaptive capacity", Global Environmental Change, 12: 25-40.

Yuda, (2013), "Mitigasi dan Adaptasi Perubahan Iklim oleh Masyarakat dalam Ketersediaan Air Minum, Laporan Penelitian, Dinas Pekerjaan Umum. 